\title{
LAS EMERGENCIAS Y CATÁSTROFES COMO RIESGO PARA LA SEGURIDAD: UNA VISIÓN DESDE LA PERSPECTIVA DEL DERECHO INTERNACIONAL PÚBLICO A LA LUZ DE LA ESTRATEGIA DE SEGURIDAD NACIONAL DE MAYO DE 2013
}

\author{
Autor: María Isabel Torres Cazorla ${ }^{1}$ \\ Profesora titular de Derecho Internacional Público y Relaciones Internacionales \\ Universidad de Málaga
}

\section{Resumen}

La Estrategia de Seguridad Nacional de 31 de mayo de 2013 contempla entre los denominados riesgos para la seguridad las emergencias y catástrofes. Dicho documento

\footnotetext{
${ }^{1}$ mtorres@uma.es.

El presente trabajo se lleva a cabo en el entorno del Proyecto del Ministerio de Educación DER2010. 14896, dirigido por el profesor Dr. Daniel García San José, de la Universidad de Sevilla, así como de la Acción COST n. IS1003 "International Law between Constitutionalisation and Fragmentation: the Role of Law in the Post-national Constellation", dirigida por el profesor Wouter Werner de la Vrije Universitet de Amsterdam.
} 
dedica poco más de tres páginas a esta temática; sobre esta base, nuestro objetivo principal es acercar al lector al fenómeno de las catástrofes y su incidencia en la seguridad, desde la óptica del Derecho Internacional Público. Las líneas que siguen constituyen una aproximación a diversas variables relacionadas con el fenómeno de las catástrofes, sus implicaciones, internacionales y para nuestro país, teniendo presente en todo momento como telón de fondo la ya mencionada Estrategia de Seguridad Nacional.

Palabras clave: catástrofes; emergencias; medioambiente; protección civil; seguridad nacional; seguridad medioambiental.

"Emergencies and Disasters as Security Risks: an Approach from the Perspective of Public International Law, taking into account the Spanish National Security Strategy (May, 2013)".

\begin{abstract}
:
The Spanish National Security Strategy, adopted on 31 May 2013, describes emergencies and disasters as security risks. Three pages of this document are devoted to this subject; this article is focused on disasters and the influence of these phenomena on security questions, from the perspective of Public International Law. It is an approach to many variables connected with disasters, their implications (from an international and national point of view), using the Spanish National Security Strategy as a backdrop.
\end{abstract}

Key Words: civil protection; disasters; emergencies; environment; environmental security; national security.

\title{
1. A MODO DE INTRODUCCIÓN
}

El actual contexto (tanto nacional como internacional) en el que vivimos, así como su imprevisibilidad, son circunstancias que permiten la proliferación de numerosos temas multidisciplinares que, sin duda alguna, constituyen objeto de una enorme preocupación, tanto de los estudiosos del Derecho Internacional Público, de los juristas en general, así como del gran público. Justamente esto es lo que sucede con la materia a la que las páginas que siguen pretenden realizar un acercamiento, siquiera provisional e intuitivo: el fenómeno de las catástrofes 
y otras cuestiones relacionadas de manera muy directa con la anterior que, sin duda alguna, constituyen un tema plagado de múltiples aristas, imprecisiones y también, precisamente por ello, un amplio campo de estudio que se abre ante los ojos del investigador.

Las páginas que siguen pretenden abordar varios frentes, encontrando todos ellos acomodo, de un modo u otro, en la Estrategia de Seguridad Nacional en la que seguidamente nos detendremos: por un lado, un análisis conceptual de la diversidad terminológica existente, de la mano de los principales instrumentos normativos que se han ocupado de los desastres y su regulación, siquiera incipiente, algunos de cuyos rasgos serán apuntados desde esta introducción; todo ello seguido por la exposición de uno de los grandes retos a los que el Derecho Internacional se enfrenta en la actualidad para hacer frente de manera eficaz a los fenómenos de esta índole (en este punto, la cuestión de la responsabilidad de proteger sale a la palestra, con las enormes dudas que ello conlleva y el debate originado sobre el particular). Ello nos permitirá apuntalar, siquiera sea de forma indiciaria, algunas conclusiones preliminares, junto con la bibliografía citada en las páginas que siguen. Por supuesto, el tema permite realizar un abordaje mucho más amplio, de imposible tratamiento en esta sede, como todo lo atinente a la protección civil y su plasmación en los diferentes órdenes (especialmente en lo que concierne a la interacción entre las fuerzas y cuerpos implicados en las actuaciones sobre el terreno $)^{2}$, así como la regulación delineada en la Unión Europea a este respecto, temas todos ellos que, en si mismo considerados, pueden dar lugar a estudios de enorme amplitud. En el presente trabajo nos referiremos a cuestiones conexas, pero sin abordar los mismos de forma específica, ante la imposibilidad material que un trabajo de estas características conlleva.

Si bien este tema no es, ni mucho menos novedoso (desastres, tanto naturales como tecnológicos y/o de naturaleza mixta se han venido produciendo prácticamente desde que el mundo es mundo) ${ }^{3}$ sí que lo es el tratamiento y la atención que, desde diversas parcelas de las Ciencias Sociales y muy especialmente desde el ámbito jurídico, se está prestando al mismo. En ese sentido, la preocupación

${ }^{2}$ De la relevancia del tema, así como de su carácter novedoso, conectado directamente con el papel de las Fuerzas Armadas en el mismo, da cuenta la reciente publicación por el Instituto Español de Estudios Estratégicos (Cuadernos de Estrategia 165), del libro España ante las emergencias y catástrofes. Las Fuerzas Armadas en colaboración con las autoridades civiles, Ministerio de Defensa, enero de 2014, cuya lectura resulta de enorme interés para el tema que nos ocupa.

${ }^{3}$ Simplemente, a modo ilustrativo de algunos de los grandes desastres que se han producido a lo largo de la historia de la humanidad, véanse a título ejemplificativo los que nos relata THOUVENIN, J.-M., "L'internationalisation des secours en cas de catastrophe naturelle", Revue Générale de Droit International Public (tomo 102, 1998-2), p. 328, donde cita, entre otros, la erupción del Vesubio en el año 79, la inundación sufrida en Países Bajos en 1424 que causó 100.000 muertos, o el terremoto de 1558 en China, en el que perecieron 850.000 personas. Ello, a modo de pequeña muestra de la relevancia de un fenómeno que no es ni mucho menos novedoso, aunque la atención que desde el Derecho Internacional Público se le esté prestando sí lo sea, al menos relativamente. 
de los ius-internacionalistas acerca de esta materia y sus múltiples vertientes, ha encontrado acomodo, tanto en la proliferación cada vez mayor de trabajos científicos sobre este particular, en los intentos de abordaje de este tema por el máximo órgano que se encarga de la "codificación y desarrollo progresivo del Derecho Internacional" - esto es, la Comisión de Derecho Internacional de Naciones Unidas (CDI, a partir de este momento $)^{4}$ - e, igualmente, en la preocupación creciente que las Organizaciones Internacionales dedican de manera específica a esta cuestión. Y ello por supuesto, sin olvidar la conexión cada vez más directa entre seguridad, medioambiente, protección civil y el papel cada vez más activo que nuestras Fuerzas Armadas juegan en este sector, objeto de enorme preocupación, como no podía ser de otra manera.

Justamente en esta línea, en relación con el último punto mencionado más arriba, se enmarca un aspecto concreto al que la Estrategia de Seguridad Nacional ${ }^{5}$ que vio la luz el 31 de mayo de 2013 alude, entre los denominados "riesgos para la seguridad": emergencias y catástrofes. La visión que el mismo ofrece acerca de dichas figuras resulta acorde a lo antedicho, cuando este documento afirma lo siguiente:

"Las catástrofes naturales siempre han golpeado a la humanidad. Pero, debido a la interdependencia que caracteriza a los riesgos y amenazas en el mundo actual, están adquiriendo nuevos rasgos y dimensiones”.

Esos "nuevos rasgos y dimensiones" adquiridos por emergencias y catástrofes -conceptos que, por otra parte, el documento no define, lo que constituye precisa-

${ }^{4}$ Ya en 2006, el programa de trabajo a largo plazo de la CDI dedicó atención a este tema, haciéndolo suyo la Asamblea General de Naciones Unidas en virtud de la Resolución 62/66, de 6 de diciembre de 2007. Ese mismo año sería elaborado un extenso documento de 158 páginas, que contiene el Memorándum de la Secretaría tendente a que el tema fuese abordado por la CDI (Doc. A/CN.4/590, de 11 de diciembre de 2007), y que sería objeto de discusión en este órgano en el período de sesiones desarrollado en 2008, año a partir del cual el tema "Protección de las personas en caso de desastre" figura en la agenda de la Comisión, de la mano de su Relator Especial, E. Valencia-Ospina.

${ }^{5}$ El documento, bajo el sugerente título "Estrategia de Seguridad Nacional. Un proyecto compartido", puede consultarse en el siguiente enlace http://www.lamoncloa.gob.es/NR/rdonlyres/0BB61AA9. 97E5-46DA-A53E-DB7F24D5887D/0/Seguridad_1406connavegacionfinalaccesiblebpdf.pdf (este vínculo web, al igual que el conjunto de los mencionados en el presente trabajo han sido objeto de consulta por última vez el día 13 de junio de 2014). En particular, la p. 34, en su apartado 10, se refiere a estos temas objeto de nuestro interés, a los que incluye entre "los riesgos y amenazas para la seguridad nacional". Junto a la cuestión de emergencias y catástrofes, que aparece en el apartado 10 de este compendio de situaciones, el documento se refiere a otras muchas, que cada vez gozan de mayor relevancia para la seguridad -nacional e internacional- tales como los conflictos armados, el terrorismo, las ciberamenazas, el crimen organizado, la inestabilidad económica y financiera, la vulnerabilidad energética, la proliferación de armas de destrucción masiva, los flujos migratorios irregulares, el espionaje, la vulnerabilidad del espacio marítimo o la vulnerabilidad de las infraestructuras críticas y servicios esenciales (vid. pp. 24-38 del documento citado).

${ }^{6}$ Vid. documento citado, p. 34. La cursiva es nuestra. 
mente una de las dificultades que el análisis de este tema comporta- y a los que se hace alusión de manera ejemplificativa en los párrafos siguientes de dicha Estrategia de Seguridad Nacional bajo la rúbrica general de "nuevos riesgos", nos ponen sobre la pista de la dimensión y relevancia que esta temática alcanza en la actualidad. Se trata además de un ámbito cuyas ramificaciones resultan impredecibles, tal vez producto del convulso escenario internacional que nos ha tocado vivir.

Pero, no solamente tenemos referencias insoslayables en el contexto internacional; nuestro ámbito interno, tal y como menciona el documento de referencia, ofrece ejemplos recientes de catástrofes naturales (seísmo de Lorca, 2011; erupciones volcánicas en la isla de El Hierro el mismo año; inundaciones en múltiples lugares de nuestra geografía, riesgo de desertificación en otras, incendios de magnitudes insospechadas, problemas derivados del uso insostenible de los recursos hídricos, enfermedades y pandemias... $)^{7}$.

No basta con ofrecer una panoplia de los problemas que afectan de un modo u otro a la seguridad en el escenario actual; hay que hacer frente a dichos problemas y marcarse objetivos que, a corto o medio plazo permitan, bien su erradicación, bien la mitigación de sus efectos cuando ello sea posible. El objetivo que la Estrategia de Seguridad Nacional 2013 plantea es el siguiente, en palabras del propio documento, que reproducimos:

"Establecer un Sistema Nacional de Protección de los ciudadanos que garantice una respuesta adecuada ante los distintos tipos de emergencias y catástrofes originadas por causas naturales o derivadas de la acción humana, sea ésta accidental o intencionada".

${ }^{7}$ Vid. documento citado, pp. 34-35. Por supuesto, la lista no es exhaustiva, y a ella habría que sumar otras situaciones también relativamente recientes, como todos los problemas sufridos durante el crudo invierno de 2014 en muy diversos puntos de nuestra geografía, los seísmos detectados en Castellón en 2013, y la eventual relación existente con el proyecto Castor de almacenamiento de gas, como meras notas de actualidad. De forma específica, respecto a los denominados "Riesgos que afectan a las zonas costeras", tanto los riesgos naturales como la erosión costera son aspectos abordados, por ejemplo, en el Protocolo relativo a la gestión integrada de las zonas costeras del Mediterráneo, adoptado en 2008, del que se puede encontrar un completo análisis en E. DEL M. GARCÍA RICO, "La gestión integrada de las zonas costeras: avances recientes”, en JUSTE RUÍZ, J., y BOU FRANCH, V. (dir.), SÁNCHEZ PATRÓN, J.M., (coord.), Derecho Internacional y Sostenibilidad Ambiental en el Mediterráneo, ed. Tirant lo Blanch, Valencia, 2013, especialmente pp. 488-489. Sobre las múltiples perspectivas desde las que se puede abordar el fenómeno de las catástrofes naturales, vid. TESTART, J., "Regards pluridisciplinaires sur les catastrophes écologiques", en Les catastrophes écologiques et le droit: échecs du droit, appels au droit, Lavieille, J.-M., BÉTAILLE, J. y PRIEUR, M., BRUYLANT, Bruselas, 2012, pp. 31-58.

${ }^{8}$ Vid. documento citado, p. 39, en la tabla ilustrativa de referencia. Exactamente esta misma idea de dotar de un enfoque integral a estos fenómenos, independientemente de su origen natural o humano, la encontramos igualmente en el documento elaborado dos años antes titulado "Estrategia Española de Seguridad. Una responsabilidad de todos”, Gobierno de España, Madrid, 2011, p. 73, al que se puede acceder en el enlace siguiente: http://www.lamoncloa.gob.es/nr/rdonlyres/d0d9a8eb-17d0-45a5-adff46a8af4c2931/0/estrategiaespanoladeseguridad.pdf. 
Mención destacable merece el intento de cobertura amplia que se pretende ofrecer con el objetivo de hacer frente a todo tipo de emergencias y catástrofes (naturales, derivadas de la acción humana y a su vez ya sean accidentales o no). Ello nos acerca a un debate abierto desde hace décadas, del que tanto los organismos internacionales como la propia doctrina se han hecho eco: un intento de clasificación de estos fenómenos, atendiendo al origen natural ${ }^{9}$ y/o tecnológico de los mismos ${ }^{10}$, junto a situaciones híbridas cada vez más frecuentes en la realidad (las denominadas catástrofes sinérgicas o $\mathrm{Na}$-Techs ${ }^{11}$, que constituyen una combinación de ambas situaciones) $)^{12}$, e inclusive fenómenos complejos como las

9 Desde la década de los sesenta, la Asamblea General de Naciones Unidas, así como el ECOSOC han venido prestando atención especialmente a la asistencia en casos de desastre natural; vid. dicha denominación, entre otras, en las Resoluciones 2034 (XX) de 7 de diciembre de 1965, 2435 (XXIII), de 19 de diciembre de 1968, 2608 (XXIV) de 16 de diciembre de 1969 y 2717 (XXV) de 15 de diciembre de 1970, todas ellas de la Asamblea General. En el marco del ECOSOC, cabe mencionar, entre otras, las Resoluciones 1533 (XLIX), de 23 de julio de 1970 y 1546 (XLIX) de 30 de julio de 1970. La Resolución 2826 (XXVI) de 14 de diciembre de 1971 amplía el ámbito, además de a los desastres naturales a otras situaciones de desastre, con lo que la óptica a seguir a partir de ese momento por Naciones Unidas adopta ese enfoque más general.

${ }^{10}$ Por ejemplo, el Centre for Research on the Epidemiology of Disasters (CRED), sigue esta clasificación en los informes anuales que presenta; concretamente, el más reciente, elaborado en 2013, respecto a los datos de 2012, señala en su p. 10 la existencia de dos categorías genéricas de desastres (naturales -a su vez divididos en cinco apartados, esto es, biológicos, geofísicos, hidrológicos, meteorológicos y climatológicos-y tecnológicos). Vid. Annual Disaster Statistical Review 2012. The Number and Trends, elaborado por Guha-Sapir, D., Hoyis, P. y Below, R., al que se puede acceder en http://reliefweb.int/sites/reliefweb. int/files/resources/ADSR_2012.pdf.

${ }^{11}$ Denominación acogida por el DOC. A/CONF.172/6, y Add.1-8, que contiene el Informe del Comité Técnico que abordó las interrelaciones entre los riesgos tecnológicos y naturales, en la Conferencia Mundial sobre la Reducción de los Desastres Naturales celebrada en Yokohama del 23 al 27 de mayo de 1994. Nadie podría imaginarse que años después, en 2011, en el mismo Estado japonés se produciría la catástrofe del efecto combinado del terremoto, tsunami y fugas radiactivas de la central de Fukushima, un claro ejemplo de este tipo de situaciones sinérgicas. Numerosos temas nucleares del Derecho Internacional, como por ejemplo el de la responsabilidad respecto de daños transfronterizos, en el que no podemos detenernos por desbordar el tema objeto de estudio, han sido analizados profusamente por la doctrina, justo a raíz de las catástrofes producidas en los últimos años. Vid., entre otros, TORRES CAZORLA, M.I., "Environmental Security: an Initial View from the Perspective of International Law", en GARCÍA RICO, E.M. y TORRES CAZORLA, M.I. (coords.), La seguridad internacional en el siglo XXI. Nuevas Perspectivas, Plaza y Valdés Editores, Universidad de Málaga, Madrid, 2011, especialmente pp. 149-152; BRATSPIES, R.M., "State Responsibility for Human-Induced Environmental Disasters", German Yearbook of International Law (vol 55, 2012), especialmente pp. 177-183, donde se hace eco de múltiples situaciones objeto de interés para el tema acaecidas recientemente. Sobre la cuestión de Fukushima, de manera particular, HANSCHEL, D., "Prevention, Preparedness and Assistance Concerning Nuclear Accidents- Effective International Legal Framework or Patchwork?", German Yearbook of International Law (vol 55, 2012), pp. 245-248.

${ }^{12}$ La dificultad que en ocasiones conlleva dicho intento de clasificación ha sido puesta de relieve por el Relator Especial de la CDI -E. Valencia-Ospina- ya desde su Informe Preliminar, al señalar que: "Para empezar, los desastres pueden dividirse en dos categorías según su causa: desastres naturales (por ejemplo, terremotos, tsunamis y erupciones volcánicas) y desastres causados por el hombre (por ejemplo, derrames de petróleo, accidentes nucleares y conflictos armados). Además, atendiendo a su duración suele distinguirse 
crisis humanitarias, a las que Naciones Unidas y de manera específica su Asamblea General han venido prestando atención desde hace décadas ${ }^{13}$. Como se ha señalado, las Estrategias de Seguridad Nacional se decantan por incluir todo este conjunto de fenómenos, ya sean de origen natural o humano, siguiendo así la tendencia que actualmente encontramos tanto en los ámbitos normativos nacionales e internacionales a los que nos referiremos en detalle en las páginas que siguen, como por la propia doctrina que ha trabajado ampliamente estos temas ${ }^{14}$.

Como no puede ser de otra forma, los objetivos a cumplir delineados por la Estrategia de 2013 llevan consigo una serie de líneas estratégicas (diez, para ser exactos) $)^{15}$ cuyos aspectos esenciales serían, grosso modo, los siguientes: 1) la prevención, tema clave al que se hace referencia al menos en cinco ocasiones; 2) el uso eficiente de los limitados recursos disponibles; 3) la coordinación y cooperación entre administraciones, internas en sus diferentes niveles (general, Comunidades Autónomas y de ámbito local), así como la toma en consideración de otros organismos más allá de nuestras fronteras (europeos e internacionales) con el objetivo de mejorar la capacidad de respuesta y la participación de España en éstos últimos; 4) la información (red de alerta nacional), y formación al respecto, así como la mejora de los instrumentos al efecto (protocolos de actuación, marco jurídico).

Como se ve, un campo de actuación inmenso, dentro del cual dos palabras parecen constituir hoy día el eje del debate, que, lejos de estar cerrado, nos ofrece un

entre desastres repentinos (por ejemplo, huracanes) y desastres paulatinos o de evolución lenta (por ejemplo, sequías, escasez de alimentos y pérdidas de cosechas). Por último, según el contexto en que ocurren, cabe distinguir entre desastres acaecidos en el marco de una emergencia simple o de una compleja. En general, por emergencia compleja se entiende una crisis humanitaria producida en un país, región o sociedad que implica una pérdida total o considerable de autoridad resultante de un conflicto interno o externo y que requiere una respuesta internacional que va más allá del mandato o la capacidad de un solo organismo o del programa en curso de las Naciones Unidas". Vid. Doc. A/CN.4/598, 5 de mayo de 2008, párr. 48, p. 18.

${ }^{13}$ Estaeslatendenciaquese observa, comoponede relieve THOUVENIN,J-.M.,"L'internationalisation...", loc. cit., p. 332, al señalar que la práctica ha evolucionado hacia el tratamiento de manera conjunta de las catástrofes naturales y otras situaciones de urgencia similares, como se desprende del propio título de la Resolución 43/131, de 8 de diciembre de 1988, de la Asamblea General ("Asistencia humanitaria a las víctimas de desastres naturales y situaciones de emergencia similares"). Ello se pone de relieve del mismo modo en la propia web de la organización donde, en lo que se refiere a Asuntos Humanitarios (http://www.un.org/es/ humanitarian/), aparece un enlace tanto a la Oficina de Coordinación de Asuntos Humanitarios (http:// www.unocha.org/), al ACNUR (http://www.acnur.org/t3/) y a la Estrategia Internacional de Reducción de Desastres (http://www.unisdr.org/).

${ }^{14}$ Meramente como muestra, véase el tratamiento exhaustivo que a este respecto realiza FERNÁN. DEZ LIESA, C.R., "Desarrollos del Derecho Internacional frente a los desastres/catástrofes internacionales", en FERNÁNDEZ LIESA, C.R. y OLIVA MARTÍNEZ, J.D., El Derecho Internacional y la Cooperación frente a los desastres en materia de Protección Civil, Dirección General de Protección Civil y Emergencias, Madrid, 2012, especialmente en pp. 18-20, donde analiza las clases de catástrofes.

${ }^{15}$ Curiosamente, cabe destacar que este tema constituye, junto con el de la seguridad energética, que lo supera por una línea estratégica más, el que mayor número de ítems señala para poner en práctica el objetivo que la Estrategia ha planificado. Vid. documento citado, concretamente el cuadro explicativo que aparece en p. 50. 
ámbito en el que, tanto los estudiosos como los prácticos tienen mucho que aportar: la prevención como pauta a seguir y la coordinación en todos los escenarios posibles (nacionales e internacionales) traducen la relevancia que la Estrategia de Defensa Nacional dedica a este tema ${ }^{16}$. Por ello, en las líneas que siguen trataremos de ofrecer algunos de los aspectos que resultan, a nuestro juicio, de interés en este sector, muchos de ellos aún por explorar.

\section{CATÁSTROFES, DESASTRES, EMERGENCIAS...: LAS IMPLICACIONES DE UNAS FIGURAS DE CONTORNOS DIFUSOS}

Un aspecto inicial que debe desvelarse al lector desde este primer momento es el siguiente: no existe una definición jurídica internacionalmente aceptada del fenómeno al que nos estamos refiriendo en estas páginas; es más, como puede verse de manera clara al realizar un acercamiento a esta temática, aún someramente, los términos que se utilizan pueden ser muchos y enormemente diversos, inclusive en lengua española, aspecto éste que se acrecienta si nos aproximamos a otras lenguas de nuestro entorno, más o menos cercano ${ }^{17}$. Quizá las más

${ }^{16}$ En este sentido, la cooperación en el marco de la protección civil "no sólo se ha generado para los casos de intervención y emergencia sino que también pretende regular y coordinar las actividades de prevención, previsión, preparación y planificación, así como la gestión postcrisis", como señala OLIVA MARTÍNEZ, J.D., "Marco Jurídico Internacional y Europeo de la Protección Civil", en El Derecho Internacional y la Cooperación, op. cit., p. 49. Por supuesto, entendida la protección civil, siguiendo a este mismo autor, como "un servicio público por el que cada Estado está llamado a proporcionar la protección y asistencia para todas aquellas personas que están bajo su jurisdicción ante cualquier tipo de accidente o de catástrofe", incluyendo también "los mecanismos con los que cuenta el Estado para la salvaguarda de los bienes culturales y el medio ambiente"; vid. OLIVA MARTÍNEZ, J.D., "Marco Jurídico Internacional y Europeo de la Protección Civil", Anuario de la Facultad de Derecho de la Universidad de A Coruña (vol. 14, 2010), p. 607. Un análisis histórico de la protección civil en España puede verse en pp. 607-608 de este mismo artículo.

17 La diversidad terminológica es ingente, tanto si nos enfrentamos a análisis doctrinales sobre la materia, como si lo hacemos respecto de documentos, ya sean éstos -en su mayoría recomendatorioselaborados a iniciativa de Organizaciones Internacionales, ya sea en el ámbito convencional -tratados internacionales, bien multilaterales, bien de índole bilateral- o inclusive normas de carácter interno. Como decimos, términos tales como desastre, catástrofe, riesgo, amenaza, emergencia, crisis, trauma, etc., son comunes y suelen ser utilizados de forma intercambiable en español; en inglés, la terminología es igualmente diversa (disaster, risk, hazard, entre otros, relacionados con conceptos como vulnerability). En ese sentido, el binomio desastres/pobreza (y por ende, vulnerabilidad conectada con el mismo) ha sido puesto de relieve desde hace décadas; valga como ejemplo la mención que desde el Programa de Naciones Unidas para el Desarrollo se realizó en 1994 sobre este punto concreto en su Informe sobre Desarrollo Humano, p. 34, recuadro 2.4, al que puede accederse en http://hdr.undp.org/sites/default/files/hdr_1994_ es_completo_nostats.pdf. El mismo señala, respecto a la preocupación por el aumento de los desastres, que "(l)os pobres están mucho más expuestos a los desastres que los ricos. (...) Los desastres en los países en desarrollo forman parte integral de su ciclo de pobreza. La pobreza provoca desastres y los desastres exacerban la pobreza. Sólo el desarrollo humano sostenible, que aumente la seguridad de los seres humanos y del planeta en que habitamos, podrá reducir la frecuencia y los efectos de los desastres naturales". 
frecuentemente utilizadas, siéndolo en diversas ocasiones como sinónimos, sean "catástrofe" y "desastre"18.

Ahora bien, las cuestiones terminológicas no deben en modo alguno empañar el hecho de que nos encontramos ante una realidad a la que se debe hacer frente y cuya relevancia -y toma de conciencia respecto a la prevención- es cada vez más mayor $^{19}$. Por ello, no resulta sorprendente el mensaje que en este sentido transmitía Valencia-Ospina, a la sazón Relator Especial de la CDI de Naciones Unidas, quien como se ha señalado lleva las riendas desde el año 2008 del tratamiento del tema titulado "Protección de las personas en caso de desastre" y que hasta la fecha ha presentando un conjunto de siete informes sobre el particular ${ }^{20}$ :

"No debe sorprender, entonces, que haya surgido una toma de conciencia colectiva y que tanto los gobiernos como organismos e instituciones no gubernamentales se hayan interesado, dentro de sus respectivas órbitas, en el análisis de los diversos aspectos del problema y la búsqueda de respuestas adecuadas. Dentro de este marco, es comprensible que se reconozca el papel central que deba jugar el Derecho, especialmente el Derecho Internacional"21.

La gran paradoja a la que nos enfrentamos es la siguiente: si bien la mayor parte de los conceptos utilizados no son propiamente términos jurídicos ${ }^{22}$, no queda más

18 Como lo hace, por ejemplo, FERNÁNDEZ LIESA, C.R., "Desarrollos del Derecho Internacional frente a los desastres/catástrofes internacionales”, Anuario de Derecho Internacional (vol. 27, 2011), especialmente pp. 210-211; este mismo autor cita el intento de distinción elaborado por PÉREZ DE ARMIÑO, K. (dir.), Diccionario de acción humanitaria y cooperación al desarrollo, Icaria editorial, 2006, pp. 187-191, donde distingue "catástrofe" como un evento natural o humano que actúa como detonante de la crisis; el "desastre" consistiría en el impacto de esa crisis, en sus perniciosas consecuencias humanas, sociales y económicas.

19 Es relevante destacar algunos datos: en el reciente informe elaborado por el CRED, al que antes se ha hecho referencia, la comparación con lo acaecido en años anteriores permite verificar que, si bien respecto de 2011 el número de desastres naturales se incrementó levemente en el mundo (un 2.3\%, pasando a 357 frente a los 349 el año anterior), el número de víctimas mortales se ha reducido drásticamente (pasando de 31.331 en 2011 a 9.655 en 2012). Vid. pp. 21 y siguientes de dicho documento, con numerosas tablas ilustrativas de dichos datos.

20 Toda la documentación relacionada con el tratamiento de este tema en la CDI hasta el momento puede consultarse en http://legal.un.org/ilc/guide/6_3.htm.

21 Vid. VALENCIA-OSPINA, E., "Prólogo", en Prieto Sanjuán, R., y Thouvenin, J.-M., Derecho Internacional y Desastres. Estudios sobre Prevención y asistencia a víctimas, CEDI, CEDIN, Grupo Editorial Ibáñez, Bogotá, 2011, p. 20.

${ }^{22}$ Como claramente ha señalado FERNÁNDEZ LIESA, C.R., "Desarrollos del Derecho Internacional...", loc.cit., p. 212, al afirmar que "(d)esde la perspectiva internacional no existe una noción jurídica internacional universalmente aceptada, aunque hay diversas definiciones", entre las que cabe destacar la que ofrece el Convenio de Tampere de 18 de junio de 1998, el Acuerdo de ASEAN sobre la gestión de desastres y la respuesta a las emergencias, o el Código de Conducta para el Movimiento Internacional de la Cruz Roja y de la Media Luna Roja (1995). Una visión de los instrumentos internacionales (tratados 
remedio que ofrecer alguna definición de los mismos que ayude a deslindar sus rasgos. Máxime cuando lo que se pretende desde diversos foros (internacionales -regionales o no, como veremos- e inclusive nacionales) es hacer frente a fenómenos complejos, para lo cual son precisas la prevención, la cooperación y la coordinación.

La Asamblea General de Naciones Unidas, desde hace ya décadas ${ }^{23}$, comenzó a preocuparse por la cuestión, instaurando lo que inicialmente fue concebido como el "Decenio Internacional para la Reducción de los Desastres Naturales"24; logro suyo fue la consagración del segundo miércoles de octubre como el "Día Internacional para la Reducción de los Desastres Naturales"25, designando posteriormente una fecha concreta -el 13 de octubre de cada año- para celebrar el que pasó a denominar "Día Internacional para la Reducción de los Desastres" (ya no exclusivamente naturales ${ }^{26}$. La continuación directa de esa idea fue asumida por la denominada Estrategia Internacional para la Reducción de los Desastres (UNISDR, en sus siglas en inglés) ${ }^{27}$, bajo cuyo patrocinio se ha elaborado en 2009 un documento que lleva por título "Terminología sobre Reducción del Riesgo de

multilaterales e inclusive instrumentos no vinculantes de diversa índole) que se han dedicado a la regulación de las situaciones de emergencia y desastre, vid. este mismo autor, en El Derecho Internacional y la Cooperación..., op. cit., pp. 22-24 especialmente.

${ }^{23}$ Prácticamente desde mediados de los años sesenta, la Asamblea General comenzó a preocuparse por estos temas, creando además un organismo dedicado en particular a la coordinación de la ayuda en caso de catástrofe natural (UNDRO). Un análisis detenido de estos primeros pasos, véase en LANGEAIS, J., Les Nations Unies face aux catastrophes naturelles: Étude du Bureau du Coordonnateur des Nations Unies pour les secours en cas de catastrophe (U.N.D.R.O.), París, L.G.D.J., 1977. Dicha tarea en la actualidad se encuentra subsumida en la OCHA (Oficina de Naciones Unidas para la Coordinación de Asuntos Humanitarios). Las funciones de esta Oficina son mucho más amplias, si bien el ámbito de las emergencias y la necesidad de ofrecer respuesta a las mismas constituye uno de sus frentes de actuación fundamentales. Véase http://www.unocha.org/what-we-do/coordination/preparedness/overview.

${ }^{24}$ Como hitos al respecto cabe mencionar, entre otros, la Resolución 42/169, de 11 de diciembre de 1987; seguida por la Resolución 43/202, de 20 de diciembre de 1988, 44/236, de 22 diciembre de 1989, la Resolución 54/219, de 3 de febrero de 2000, la Resolución 56/195, de 21 de diciembre de 2001, entre otras muchas, a las que deben sumarse resoluciones "temáticas" cuyo objetivo prioritario consistía en afrontar "desastres" concretos (por ejemplo, tendentes a incentivar la cooperación internacional para reducir el impacto del fenómeno del "Niño", cuya senda se inicia a partir de la Resolución 53/185, de 1998). De igual manera, el binomio desastres naturales/vulnerabilidad también se ha dejado patente en diversas Resoluciones de la Asamblea General (marcando un hito la Resolución 58/215, de 27 de febrero de 2004, seguida de otras muchas). Vid. al respecto el conjunto de estas Resoluciones en el apartado creado al efecto en http://www.unisdr.org/we/inform/resolutions-reports.

${ }^{25}$ En virtud de la Resolución 44/236, de 22 de diciembre de 1989, anteriormente citada, en su párrafo 2.

${ }^{26}$ La Resolución 64/200, de 21 de diciembre de 2009 consagra esta fecha y la denominación de dicha jornada, en su párrafo 28.

${ }^{27}$ La denominada United Nations International Strategy for Disasters Risk Reduction, como un paso adelante respecto a la idea de la instauración del Decenio Internacional para la Reducción de los Desastres Naturales, que además se concibe de manera más amplia, referida a los riesgos de desastre, sin distinction acerca de si los mismos tienen un origen en la naturaleza o no es así. El acento se pone en su reducción, sea cual fuere su origen. 
Desastres"28 y que puede resultar enormemente útil para el desarrollo de los interrogantes que aquí afrontamos. A nuestro parecer, dos de los diferentes términos que dicho documento trata de definir pueden traerse a colación, en consonancia con los pasos que en él ámbito internacional tratan de darse a este respecto; serían, por un lado, la definición de lo que se entiende por desastre (y sus equivalentes disaster y catastrophe en las versiones del documento en español, inglés y francés, respectivamente), enunciada del modo siguiente:

"Una seria interrupción en el funcionamiento de una comunidad o sociedad que ocasiona una gran cantidad de muertes al igual que pérdidas e impactos materiales, económicos y ambientales que exceden la capacidad de la comunidad o la sociedad afectada para hacer frente a la situación mediante el uso de sus propios recursos"29.

En el contexto de la CDI, el Segundo Informe que presentó su Relator Especial en $2009^{30}$ propuso una definición de "desastre", con la que intentaba, partiendo de que no nos encontramos ante un concepto jurídico, delinear el tema a los efectos de avanzar en los trabajos en el seno de la Comisión. Dicho proyecto de artículo 2, bajo el título "Definición de desastre", decía así:

"Por "desastre" se entenderá una perturbación grave del funcionamiento de la sociedad, con excepción de las situaciones de conflicto armado, que provoque pérdidas humanas, materiales o ambientales importantes y generalizadas".

La definición propuesta por el Relator Especial pretendía, por un lado, ceñir el tema objeto de análisis por parte de la CDI (dejando a un lado las situaciones de conflicto armado, que gozan de su régimen jurídico propio) y, por otro, ofrecer una definición amplia (que difería, por ejemplo, de la contemplada en la Terminología mencionada al no hacer referencia ésta última al desbordamiento de la capacidad de la comunidad o sociedad afectada, y en la utilización de "o" en vez de "y", al referirse al tipo de pérdidas sufridas, ya sean éstas humanas, materiales o ambientales). Ahora bien, cuando dicha propuesta pasó al Comité

${ }^{28}$ Dicho documento, a cuya versión en español se puede acceder en el enlace http://www.unisdr.org/ files/7817_UNISDRTerminologySpanish.pdf, puede además consultarse en el conjunto de lenguas oficiales con las que trabaja Naciones Unidas (inglés, francés, español, árabe, chino y ruso). Sin duda alguna, resulta un instrumento útil y práctico que, además, contiene una equivalencia terminológica al inglés al final del mismo.

${ }^{29}$ Vid., documento citado, pp. 13-14 en su versión española. Si nos remitimos a lo que el Diccionario de la Real Academia de la Lengua Española determina en este sentido, vemos una similitud patente: mientras catástrofe se define como "suceso infausto que altera gravemente el orden natural de las cosas", desastre sería "una desgracia grande, un suceso infeliz y lamentable". Vid. ambas definiciones en http:// www.rae.es/recursos/diccionarios/drae.

30 Vid. Doc. A/CN.4/215, de 7 de mayo de 2009, párr. 45, p. 16. 
de Redacción ${ }^{31}$, como proyecto de artículo 3, sus contornos habían cambiado bastante, desapareciendo buena parte de esas diferencias que comentamos e introduciendo ciertos elementos "perturbadores", lo que ha provocado críticas que cabe destacar ${ }^{32}$. El texto aprobado provisionalmente por dicho Comité de Redacción decía así:
"Se entiende por "desastre" un evento o serie de eventos calamitosos que ocasionan numerosas víctimas, grave infortunio y grandes sufrimientos hu- manos o daños materiales o ambientales en gran escala, con la consiguien- te perturbación grave del funcionamiento de la sociedad"33.

Bien es cierto que resulta enormemente complejo ofrecer una definición operativa; de hecho, tanto la doctrina ${ }^{34}$ como algunos textos internacionales han hecho aproximaciones a esta noción en diversas ocasiones, destacando como elementos comunes la gravedad de la situación ${ }^{35}$, la relevancia de las pérdidas sufridas y el carácter generalizado de las mismas.

${ }^{31}$ Doc. A/CN.4/L.758, de 24 de julio de 2009.

${ }^{32}$ Como afirma THOUVENIN, J.-M., "La définition de la catastrophe par la CDI: vers une catastrophe juridique?", en PRIETO SANJUÁN, R., y THOUVENIN, J.-M., Derecho Internacional y Desastres. Estudios sobre Prevención y asistencia a víctimas, op. cit., criticando, entre otros aspectos, la condición de "perturbación grave del funcionamiento de la sociedad", que introduce un elemento de subjetividad que puede conducir al absurdo (vid. p. 47). El autor ofrece, a modo indiciario, un intento de definición que permitiría superar algunas de las críticas que formula al intento de definición antedicho, proponiendo como alternativa la siguiente: «(t)oute situation provoquée par une calamité ou une succession d'événements qui a pour effet actuel ou raisonnablement prévisible de causer des pertes massives en vies humaines, de graves souffrances humaines et une détresse aigüe, ou des dommages matériels ou environnementaux de grande ampleur» (p. 50). Elimina de este modo esa idea de perturbación grave de la sociedad que, en si misma, podría resultar perturbadora, valga la redundancia.

${ }^{33}$ Vid. Doc. citado, p. 2. El proyecto de artículo 4 señala que "(e)l presente proyecto de artículos no se aplica a las situaciones en que son aplicables las normas de derecho internacional humanitario", en clara alusión a lo que antes comentábamos: los conflictos armados salen fuera del escenario que la CDI pretende abordar.

${ }^{34}$ Desde hace décadas existe preocupación doctrinal sobre estas cuestiones; así, entre otros, véanse MACALISTER-SMITH, P., International Humanitarian Assistance. Disaster Relief Actions in International Law and Organization, Martinus Nijhoff Publishers, Dordrecht, Boston, Lancaster, 1985; una década más tarde, cabe destacar los trabajos desarrollados en el Centro de Estudios e Investigación de la Academia de Derecho Internacional de La Haya, bajo la dirección de Leben, Ch. y Caron, D.D., Les aspects internationaux des catastrophes naturelles et industrielles/The International Aspects of Natural and Industrial Catastrophes, Martinus Nijhoff Publishers, Dordrecht, Boston, Londres, 1996, así como el concepto de catástrofe que se deriva de estos trabajos, en op. cit., pp. 20-21: "Un événement souvent imprévisible ou une situation durable qui produit des dommages immédiats ou différés aux personnes, aux biens ou à l'environnement, et d'une ampleur telle qu'ils appellent une réaction solidaire de la communauté nationale et/ou internationale".

${ }^{35}$ Por ejemplo, la Decisión n ${ }^{\circ}$ 131/2013/UE del Parlamento Europeo y del Consejo, de 17 de diciembre de 2013, relativa a un Mecanismo de Protección Civil de la Unión (DOUE L 347, de 20 de diciembre de 2013), define en su artículo 4 el término catástrofe mencionando la gravedad, pero no otros aspectos que contemplan definiciones antes señaladas. A los efectos de la citada decisión lo será " $(t)$ oda situación que tenga o pueda tener efectos graves para las personas, el medio ambiente o los bienes, incluido el patrimonio cultural”. 
Si traemos a colación el documento que constituye el eje central de este trabajo, esto es, la Estrategia de Seguridad Nacional de mayo de 2013, recordemos que en él se citan dos conceptos, si bien sin definir ninguno de ellos (catástrofes, que de algún modo podría entenderse como sinónimo de desastre, conforme a la definición antedicha, junto con el de emergencia). Respecto de éste último, la "Terminología" a la que se ha aludido anteriormente, ofrece una definición que pudiera resultar útil, de lo que se concibe como "Gestión de emergencias" (Emergency Management, en inglés, mesures d'urgence, en francés $)^{36}$. El comentario a dicho término curiosamente define a su vez el término "emergencia", y lo equipara en ocasiones al de "desastre", si bien también matiza la menor gravedad que el primero parece revestir (cuando se gestiona correctamente) del modo siguiente:

"Una crisis o emergencia es una condición amenazante que requiere de la toma de acciones urgentes. Una acción eficaz de emergencia puede evitar que un evento escale hasta el punto de convertirse en un desastre. La gestión de emergencias incluye planes y disposiciones institucionales para comprometer y guiar los esfuerzos del gobierno, de las organizaciones no gubernamentales, de las entidades voluntarias y de las agencias privadas de forma coordinada e integral para responder a todas las necesidades relativas a una emergencia. A veces la expresión "gestión de desastres" también se utiliza en vez de "gestión de emergencias"37.

Una línea similar a seguir la podemos observar en algunos instrumentos de nuestro entorno cercano; valga como muestra el Convenio entre el Reino de España y la República Francesa en materia de protección y de seguridad civil, hecho en Perpiñán el 11 de octubre de $2001^{38}$. Su artículo 1 nos describe el objeto y ámbito de aplicación, que no es otro que la cooperación referida a "la previsión y prevención de los riesgos naturales y tecnológicos graves, a la formación de los agentes de protección y seguridad civil y a la asistencia mutua en caso de catástrofes o de accidentes graves". La definición que el citado Convenio provee de los términos que aquí nos interesan se refiere en su art. 2 a la noción de "situación de urgencia", entendiendo por tal "la producida por una catástrofe de origen natural o tecnológico, que tenga consecuencias graves desde el punto de vista humano

36 Vid., documento citado, p. 18 de la versión española, donde define la "gestión de emergencias" como "(1)a organización y la gestión de los recursos y las responsabilidades para abordar todos los aspectos de las emergencias, especialmente la preparación, la respuesta y los pasos iniciales de la rehabilitación".

${ }^{37}$ Ibid., p. 18. La cursiva es nuestra.

${ }^{38}$ BOE núm. 159, de 4 de julio de 2003; el mismo deroga el Convenio de 14 de julio de 1959, sobre asistencia mutua entre los servicios contra incendios y de socorro franceses y españoles, así como los acuerdos complementarios al mismo de 1973 y 1978. 
o que pueda producir un fuerte impacto medioambiental”. De dicha definición parece desprenderse que la catástrofe es el fenómeno desencadenante, mientras que la urgencia (que podría equipararse a emergencia, por referirnos a otro término utilizado frecuentemente en otros instrumentos, como veíamos) aludiría a las consecuencias derivadas de dicha situación.

Aunque menos explícito en este sentido, al no contener una definición como en el caso anterior, pero tratando de ampliar la cooperación bilateral entre vecinos siguiendo una senda muy similar a lo acaecido en el caso francés, cabe citar el Protocolo celebrado casi una década antes que el realizado con nuestros vecinos galos, entre el Reino de España y la República Portuguesa sobre Cooperación Técnica y Asistencia Mutua en Materia de Protección Civil, hecho en Évora el 9 de marzo de $1992^{39}$. El "envío de socorros en caso de accidente grave, emergencia o catástrofe", conforme a su parte Preambular, pero sin definir dichas situaciones, así como "la solicitud de ayuda, en régimen de reciprocidad", "en casos de emergencia o catástrofe, o en previsión de éstas", se constituye como elemento central de dicha cooperación bilateral, conforme a lo estipulado en el art. 3 del citado Convenio.

Los anteriormente mencionados son simplemente dos ejemplos llevados a cabo por España de los múltiples existentes ${ }^{40}$ que intentan sentar las bases de la cooperación bilateral para prevenir y hacer frente a las situaciones mencionadas, de los cuales se desprende la utilización de términos diversos ${ }^{41}$ (calamida-

39 BOE núm. 175, de 23 de julio de 1993; celebrado bajo la cobertura del Tratado de amistad y cooperación bilateral con nuestros vecinos de 22 de noviembre de 1977, y que además deja sin efecto un tratado previo más limitado, de forma similar a lo acaecido en el caso francés: el Convenio de 31 de marzo de 1980, de Asistencia Mutua entre los Servicios contra Incendio y de Socorro Portugueses y Españoles, firmado en Lisboa (BOE núm. 123, de 22 de mayo de 1980). Para hacer frente a dicho objetivo específico se adopta el Protocolo adicional sobre ayuda mutua en caso de incendios forestales en zonas fronterizas, adoptado en los términos del artículo 8 del Protocolo entre el Reino de España y la República Portuguesa sobre cooperación técnica y asistencia mutua en materia de Protección Civil, firmado el 21 de julio de 2004 (la información al respecto, junto con el conjunto de medidas de cooperación transfronteriza adoptadas en diversas materias, véase en http://www.magrama.gob.es/es/ministerio/funciones-estructura/ organizacion-organismos/ministerio-exterior/consejerias/europa/portugal/memorando/, así como en el enlace http://www.proteccioncivil.org/relaciones-bilaterales).

${ }^{40}$ Es una práctica muy extendida que, en los Convenios bilaterales de Amistad y Cooperación celebrados por nuestro país se contenga alguna referencia, aunque sea de carácter general, a la asistencia y protección civil en caso de emergencias y desastres. Sobre los acuerdos bilaterales sobre este sector, de amplio calado, que rebasa con mucho los objetivos del presente trabajo puede verse, entre otros, GONZÁLEZ VEGA, J.A., "En torno a recientes manifestaciones de la práctica convencional española en materia de tratados de amistad y cooperación", Revista Española de Derecho Internacional (vol. XLVI, 1994), pp. 425-432.

${ }^{41}$ Meramente a modo de ejemplo, podemos citar el Convenio de Cooperación entre el Reino de España y la República Argentina, para la previsión, prevención y asistencia mutua en caso de calamidades, firmado "ad referendum" en Madrid el 3 de junio de 1988, aplicado provisionalmente desde dicha fecha y cuya entrada en vigor se produjo el 1 de septiembre de 1992 (vid. BOE núm. 181, de 31 de julio de 1991 y núm. 168, de 14 de julio de 1992); el Convenio sobre cooperación técnica y asistencia mutua en materia de Protección Civil entre el Reino de España y el Reino de Marruecos, firmado en Rabat el 21 de enero de 1987 (BOE núm. 45, de 22 de febrero de 1993), que entró en vigor el 28 de diciembre de 1992; de 
des, emergencias, catástrofes, entre otros). Concretamente, el acuerdo bilateral hispano-ruso ofrece una definición del término "catástrofe" asimilable a algunas a las que se ha hecho referencia con anterioridad, al señalar en su art. 1 como tal "todo suceso de origen natural o tecnológico que puede causar o cause pérdidas importantes de vidas, perjuicios a la salud, daños a bienes o al medio ambiente, importantes pérdidas materiales y la alteración de la actividad vital de las personas". La idea de prevención, así como la actuación a posteriori, se desprenden de la citada definición, con la utilización de "puede causar o cause", señalada en cursiva por nuestra parte para resaltar dicho aspecto.

Igualmente, la cooperación transfronteriza conforma un escenario de gran importancia para España, también en este sector. En particular, el Pacto de Ayuda Mutua y los Protocolos de Actuación Conjunta, realizados en Oporto el 25 de octubre de 2013, en el marco de la cooperación hispano-lusa, bajo de la denominación "ARIEM112" deben ser objeto de mención ${ }^{42}$. El mismo contiene "el proyecto de carácter interregional ARIEM-112 (Asistencia Recíproca Interregional en Materia de Emergencias)", con el objetivo de establecer "un mecanismo de colaboración entre los servicios de gestión de emergencias entre las zonas implicadas en el proyecto (zonas limítrofes entre Galicia, Castilla y León y Portugal)"43.

Resultan dignas de tener en cuenta las diferentes clasificaciones de emergencias que se realizan en dicho documento, atendiendo a las actuaciones que revisten mayor importancia para ambas partes: riesgos naturales (inundaciones, nevadas, sequías y terremotos); accidentes (subdivididos a su vez en accidentes en medios de transporte - terrestre, aéreo, ferroviario o acuático- y accidentes en transporte de mercancías peligrosas); una tercera categoría denominada riesgos mixtos (subdividida en cinco categorías a su vez: 1) colapso total o parcial en estructuras -rotura de presas, daños en gasoductos-; 2) incendios forestales -con

igual modo, el Acuerdo entre el Gobierno del Reino de España y el Gobierno de la Federación de Rusia sobre cooperación en el ámbito de la prevención de catástrofes y asistencia mutua en la mitigación de sus consecuencias, hecho "ad referendum" en Madrid el 14 de junio de 2000 (BOE núm. 153, de 27 de junio de 2001), cuya entrada en vigor se produjo el 30 de junio de ese mismo año.

42 Véase dicho texto en http://www.ariem112.eu/Contenido/PACTOS\%20DE\%20AYUDA\%20 MUTUA.pdf.

${ }^{43}$ A este respecto debe mencionarse el relevante papel que juega la Unión Europea en lo que a la puesta en práctica del número europeo de emergencias 112 respecta, en funcionamiento desde 1991 (http://ec.europa.eu/echo/policies/disaster_response/112_en.htm). Acerca de este tema concreto, así como del conjunto normativo y de puesta en práctica de medidas para hacer frente a los desastres de manera coordinada en el ámbito de la Unión Europea, entre otros, VEGA FERNÁNDEZ, E., "La Unión Europea frente a las catástrofes: ¿es factible una unidad multinacional europea para emergencias?", en http://www.ieee.es/Galerias/fichero/colaboraciones/2011/UE_FrenteaCastratofes_OPEX.pdf, especialmente pp. 21-33; TORRES CAZORLA, M.I., "Las catástrofes: una visión desde la regulación internacional y de la Unión Europea", en VI Jornadas de Seguridad, Defensa y Cooperación. Libro de Actas, 13, 14 y 15 de noviembre de 2012, Foro para la Paz en el Mediterráneo y SPICUM, Málaga, 2013, especialmente pp. 45-51. 
o sin viviendas; 3 ) incendios urbanos e industriales; 4) vertidos de sustancias contaminantes; y 5) accidentes en instalaciones industriales (esto es, accidentes en industrias con sustancias peligrosas). En cuarto lugar se contempla la protección y asistencia a personas (búsqueda y rescate de personas, tanto terrestre como acuático); la quinta posibilidad es la realización de operaciones (ejercicios o simulacros o situaciones especiales, caracterizadas éstas últimas por no estar catalogadas en las anteriores, bien por su tipología o su criticidad); finalmente, se contemplan los denominados planes de protección civil (bien mediante la activación de planes especiales o de planes territoriales) ${ }^{44}$.

El análisis antedicho, yendo de lo general a lo particular, no estaría del todo completo si no hiciésemos mención a una norma interna española elaborada recientemente, en la que también se hace alusión, si bien de forma indirecta, pues no es ni mucho menos su objetivo principal, a la protección civil y a la necesidad de dar respuesta a las catástrofes. Nos referimos a la Ley 2/2014, de 25 de marzo, de la Acción y del Servicio Exterior del Estado ${ }^{45}$. Una palabra clave para nuestra temática se encuentra reiterada en nada menos que veinticinco ocasiones a lo largo del texto: coordinación. Asimismo, el art. 19.1 de la citada Ley, referido a la "Acción exterior en materia de seguridad pública y asuntos de interior", menciona la cooperación con terceros Estados en materia de protección civil; su art. 24, referido a la "Acción exterior en materia de cooperación al desarrollo", plantea como orientación de la misma "dar una respuesta de calidad a las crisis humanitarias". En el ámbito institucional, el denominado Grupo de emergencia consular, regulado en el art. 40 resulta igualmente digno de mención ${ }^{46}$.

${ }^{44}$ Información toda ella contenida en el documento http://www.ariem112.eu/Contenido/PACTOS\%20 DE\%20AYUDA\%20MUTUA.pdf, pp. 5-6, que se corresponde con el Anexo II de dicho documento.

${ }^{45}$ BOE núm. 74, de 26 de marzo de 2014.

${ }^{46}$ Dicho artículo 40 dice así: "1. Para garantizar la asistencia y protección debida a los ciudadanos españoles en el exterior, el Consejo de Política Exterior constituirá en su seno un grupo de emergencia consular, presidido por el Ministro de Asuntos Exteriores y de Cooperación, cuando se produzca una situación de crisis bélica, de seguridad, desastre natural, de emergencia sanitaria o alimentaria o de cualquier otra índole, que requiera la coordinación de distintos órganos y organismos de la Administración General del Estado (la cursiva es nuestra).

Dicho grupo se constituirá cuando la situación que afecte a los españoles en el exterior no esté siendo objeto de estudio o gestión por cualquier otro grupo o comisión con competencias específicas en la materia. Se integrará en dicho grupo un representante de la Secretaría de Estado de Comunicación.

2. El grupo elevará las recomendaciones oportunas al Presidente del Gobierno sobre las medidas y actuaciones que considere necesarias o convenientes para prestar la asistencia y protección a los españoles afectados.

3. Cuando el Gobierno, en una situación de emergencia consular, decida intervenir en operaciones de asistencia en el extranjero, que comporten la utilización de recursos presupuestarios del Estado, podrá exigir el reembolso de la totalidad o parte de los mismos a quienes se hayan expuesto voluntariamente a riesgos sobre los que el Ministerio de Asuntos Exteriores y de Cooperación informa en sus recomendaciones de viaje, publicadas y actualizadas puntualmente, en relación con las condiciones de seguridad en los distintos Estados y regiones del mundo". 
Por supuesto, la Estrategia de Seguridad Nacional de 2013 señala las líneas de acción estratégica, conformando así una declaración del Gobierno de los "principios que deben orientar la política pública de protección civil", revisando así la Estrategia previa de $2011^{47}$.

Todo lo anteriormente dicho viene a poner de relieve la relevancia de un tema que se sitúa, sin duda alguna, en un ámbito que podemos denominar "multinivel", al revestir el mismo implicaciones locales ${ }^{48}$, regionales ${ }^{49}$, nacionales ${ }^{50}$, e internacionales, y recibir un tratamiento desde los diferentes escenarios, ámbitos todos ellos desde los que se le viene prestando atención desde hace décadas. Los últimos años, sin embargo, parecen acrecentar los esfuerzos de cooperación, en diversos frentes, de los que la Unión Europea ${ }^{51}$ no es ni mucho menos ajena.

47 Si bien, como señala F. TALAVERA ESTESO, "El Sistema Nacional de Protección Civil", en España ante las emergencias y catástrofes. Las Fuerzas Armadas en colaboración con las autoridades civiles, op. cit., p. 52, "entra así la protección en el reducido grupo de estrategias gubernamentales que garantizan la seguridad de España, de sus habitantes y ciudadanos", la misma requiere de la promulgación de "la ley orgánica de seguridad nacional que anuncia, pero es una declaración del Gobierno de los principios que deben orientar la política pública de protección civil".

${ }^{48}$ El primer frente en el que se suele actuar cuando acaece un fenómeno de esta índole es el del lugar donde se ha producido el mismo, mediante los servicios de protección civil. En el caso de España, la Unidad Militar de Emergencias cobra también una importancia vital, ofreciendo su colaboración tanto en el exterior como en el ámbito de la Administración General del Estado, Autonómica y Local. Toda la información al respecto, véase en http://www.defensa.gob.es/ume/que-es/.

${ }^{49} \mathrm{Y}$ todo ello sin que hagamos referencia en este trabajo, por desbordar la temática y extensión del presente estudio, a los textos elaborados por las diferentes Comunidades Autónomas relativos a los servicios de protección civil respectivos y su actuación, tanto de manera preventiva como para hacer frente a las situaciones críticas que se presenten.

${ }^{50}$ Como mera muestra relativamente reciente de normas internas adoptadas en España para hacer frente a algunas situaciones acaecidas en nuestro país en los últimos años (incendios forestales, volcanes, entre otros), se pueden citar el Real Decreto-ley 25/2012, de 7 de septiembre, por el que se aprueban medidas urgentes para paliar los daños producidos por los incendios forestales y otras catástrofes naturales ocurridos en varias comunidades autónomas (BOE núm. 217, de 8 de septiembre de 2012), o la Resolución de 30 de enero de 2013, de la Subsecretaría, por la que se publica el Acuerdo de Consejo de Ministros de 25 de enero de 2013, por el que se aprueba el Plan Estatal de Protección Civil ante el Riesgo Volcánico (BOE núm. 36, de 11 de febrero de 2013).

${ }^{51}$ El art. 196 del TFUE, señala que "(l)a Unión fomentará la cooperación entre los Estados miembros con el fin de mejorar la eficacia de los sistemas de prevención de las catástrofes naturales o de origen humano y de protección frente a ellas" (la cursiva es nuestra). En el ámbito de la protección civil, la UE ha llevado a cabo numerosos desarrollos, especialmente desde 2001, que culmina con la reciente Decisión n 1313/2013/UE del Parlamento Europeo y del Consejo de 17 de diciembre de 2013 relativa a un Mecanismo de Protección Civil de la Unión (DOUE L 347 de 20 de diciembre de 2013). Sobre la evolución de esta cuestión, que sobrepasa con creces el objetivo de este trabajo, véanse, entre otros, TORRES CAZORLA, M.I., "La Comunicación de la Comisión Europea de 2010: nuevas medidas para mejorar la reacción de la UE en caso de catástrofe", en PRIETO SANJUÁN, R. y THOUVENIN, J.-M. (eds.), Derecho Internacional y Desastres, op. cit., pp. 85-110; igualmente Kotzur, M., "European Union Law on Disaster Preparedness and Response", 55 German Yearbook of International Law (2012), pp. 253-278; una descripción completa del Mecanismo Europeo de Protección Civil y sus pautas de funcionamiento, vid. en OLIVA MARTÍNEZ, J.D., "Marco Jurídico Internacional...", en El Derecho Internacional y la Cooperación frente a los desastres en materia de Protección Civil, op. cit., pp. 76-82. 
Un aspecto relevante que se desprende de la Estrategia de Seguridad Nacional, en lo que concierne al tema que nos ocupa es la toma de conciencia acerca de la necesidad de que el Estado -en sus múltiples acepciones, esto es, incluyendo los diferentes organismos y administraciones vinculados al mismo- sea quien, de manera prioritaria, se ocupe de hacer frente a estos problemas. Debemos permanecer alerta en este sentido, corroborando así totalmente la advertencia que en su día formulaban Fernández Liesa y Oliva Martínez, con la que estamos completamente de acuerdo, al señalar lo siguiente:

"La crisis económica y financiera que atenaza las posibilidades de desarrollo en gran parte del planeta, puede suponer además un cuestionamiento del papel del Estado como garante de la seguridad frente a las catástrofes coincidiendo con la reducción de los presupuestos públicos lo que puede debilitar los mecanismos de protección civil y específicamente de los sistemas de prevención, previsión de riesgos y gestión de las crisis. Algunos gobiernos pueden en ese contexto verse tentados o presionados a llevar a cabo determinados procesos de "privatización" de la prevención o la atención a las víctimas de catástrofes, primando la acción de empresas u organizaciones de la sociedad civil que si bien deben jugar un papel complementario nunca deberían sustituir al Estado"52.

Acerca de la peligrosa deriva que el Derecho Internacional experimenta ya nos alertaba, hace más de una década, el profesor Rodríguez Carrión, al afirmar:

\begin{abstract}
"Quizás estemos viviendo un derecho internacional que posiblemente esté perdiendo el reto de la solidaridad para acentuar desigualdades inaceptables, desigualdades cuya misma existencia es negada o estimada como solucionable con la adopción de recetas que en el primer mundo dieron obvio y óptimo resultado. También en la sociedad internacional parece haberse establecido, como en las sociedades internas, una especie de pensamiento único como panacea de cualesquiera tensiones" ${ }^{\prime 3}$.
\end{abstract}

La reivindicación de un carácter más social del Derecho Internacional, ya planteada por insignes maestros ${ }^{54}$, no debe ser obviada, sino reiterada día a día. Y para

52 Como señalan en su "Presentación”, FERNÁNDEZ LIESA, C.R. y OLIVA MARTÍNEZ, J.D., El Derecho Internacional y la Cooperación frente a los desastres en materia de Protección Civil, op. cit., pp. 7-8.

53 RODRÍGUEZ CARRIÓN, A.J., El Derecho Internacional en el umbral del siglo XXI, Lección de Apertura del Curso Académico1999-2000, Universidad de Málaga, 1999, p. 74.

${ }^{54}$ Conforme a lo expresado por CASADO RAIGÓN, R., Derecho Internacional. Parte General, Tecnos, Madrid, 2012, pp. 38-39, ofreciendo el pensamiento de los profesores J.A. Carrillo Salcedo y M. Bedjaoui, conectados ambos con la idea anteriormente mencionada. 
ello, sin lugar a dudas las Organizaciones internacionales, tanto universales, desde el escenario onusiano y su familia, como en el plano regional, llevan jugando un papel insoslayable desde hace décadas. Eso desde luego no nos debe conducir al conformismo, sino todo lo contrario, a una apuesta decidida por la institucionalización, por la cooperación, la coordinación y la prevención, junto con la asistencia necesaria en situaciones de catástrofe y emergencias.

\section{3. ¿UN DERECHO INTERNACIONAL PREOCUPADO QUE TRATA DE HACER FRENTE A UN SISTEMA COLAPSADO?}

En las últimas décadas, el Derecho Internacional se encuentra en una encrucijada $^{55}$, y el tema que nos ocupa no podía, ni mucho menos, sentirse ajeno a esta tendencia. La irrupción de conceptos tales como la "responsabilidad de proteger" 56 y la disyuntiva acerca de la posibilidad de delinear sus contornos e inclusive, el dilema acerca de extender dicha figura a situaciones como las que nos ocupan no resulta ni mucho menos ajeno, como veremos a continuación.

A $b$ initio, un abordaje del tema nos conduce a la conclusión de que la denominada "responsabilidad de proteger" ${ }^{57}$, como concepto emergente, no resultaría

${ }^{55}$ Parafraseando el título de la obra de GUTIÉRREZ ESPADA, C., y CERVELL HORTAL, M.J., El Derecho Internacional en la encrucijada. Curso General de Derecho Internacional Público, ed. Trotta, Madrid, $3^{\mathrm{a}}$ ed, 2012.

${ }^{56}$ Si bien este principio fue unánimemente adoptado por los Jefes de Estado y de Gobierno en la Cumbre Mundial de Naciones Unidas de 2005, sus antecedentes se remontan mucho más allá en el tiempo, existiendo especialmente desde los años noventa diversos intentos desde el escenario onusiano, a iniciativa de diferentes Estados e inclusive en foros multilaterales más allá del contexto de Naciones Unidas. Sobre este concepto resulta de interés particular la obra La responsabilité de protéger, Colloque de Nanterre, Editions A. Pedone, París, 2008; respecto de los orígenes de esta noción vid. en dicha obra THOUVENIN, J.-M., "Genèse de l'idée de responsabilité de protéger”, pp. 21-38; la evolución de esta cuestión, ha sido objeto de atención en el mismo foro, mediante la obra colectiva de CHAUMETTE, A.L., y THOUVENIN, J.M. (dirs.), La responsabilité de protéger, dix ans après, Pedone, París, 2013.

57 Por supuesto, el tema de la "Responsabilidad de Proteger" desborda con mucho el objetivo del presente trabajo, por lo que, para conocer su contenido en detalle remitimos al siguiente enlace donde se contemplan todos los documentos relevantes que se han adoptado en el contexto de $\mathrm{Na}$ ciones Unidas, y en particular de la Asamblea General, donde el debate sobre la cuestión ha tratado de esclarecer los contornos de esta figura desde que en el Documento Final de la Cumbre Mundial de 2005 se definiesen algunos de sus rasgos principales (A/RES/60/1, párrs. 138-140), en http://www. un.org/es/preventgenocide/adviser/responsibility.shtml. La polémica intervención en Libia en virtud de la Resolución 1973 de 17 de marzo de 2011 del Consejo de Seguridad ha traído a la palestra, sin duda alguna, una "revitalización de la cuestión", así como, en el caso de Siria, ha llevado a adoptar soluciones respecto del uso de armas químicas y su limitación, a partir de la Resolución 2118, de 27 de septiembre de 2013, así como a la creación de corredores humanitarios, tras la aprobación de la Resolución 2139, de 23 de febrero de 2014. Sobre la primera de las cuestiones, vid., entre otros, ALCAIDE FERNÁNDEZ, J., "La situación en Libia y el Consejo de Seguridad", El Cronista del Estado Social y Democrático de Derecho (núm. 20, 2011), pp. 52-59; GUTIÉRREZ ESPADA, C., "La Unión Europea ante la Resolución 1973 (2011) del Consejo de Seguridad, su aplicación práctica en 
aplicable en casos de emergencias y catástrofes de especial gravedad. La lectura atenta del Documento Final de la Cumbre Mundial de 2005, donde se delinearon los rasgos básicos de lo que se concibió como "responsabilidad de proteger" nos lleva a abordar los siguientes aspectos (véase especialmente la referencia a las situaciones a las que se pretende hacer frente de manera particular):

"138. Cada Estado es responsable de proteger a su población del genocidio, los crímenes de guerra, la depuración étnica y los crímenes de lesa humanidad. Esa responsabilidad conlleva a la prevención de dichos crímenes, incluida la incitación a su comisión, mediante la adopción de las medidas apropiadas y necesarias. Aceptamos esa responsabilidad y convenimos en obrar en consecuencia. La comunidad internacional debe, según proceda, alentar y ayudar a los Estados a ejercer esa responsabilidad y ayudar a las Naciones Unidas a establecer una capacidad de alerta temprana.

139. (...) estamos dispuestos a adoptar medidas colectivas, de manera oportuna y decisiva, por medio del Consejo de Seguridad, de conformidad con la Carta, incluido su Capítulo VII, en cada caso concreto y en colaboración con las organizaciones regionales pertinentes cuando proceda, si los medios pacíficos resultan inadecuados y es evidente que las autoridades nacionales no protegen a su población del genocidio, los crímenes de guerra, la depuración étnica y los crímenes de lesa humanidad. (...)También tenemos intención de comprometernos, cuando sea necesario y apropiado, a ayudar a los Estados a crear capacidad para proteger a su población del genocidio, los crímenes de guerra, la depuración étnica y los crímenes de lesa humanidad y a prestar asistencia a los que se encuentren en situaciones de tensión antes de que estallen las crisis y los conflictos" $"$.

la "guerra civil" en Libia y el post-conflicto", en BLANC ALTEMIR, A. (dir.), Las Relaciones entre las Naciones Unidas y la Unión Europea. Seguridad, Cooperación y Derechos Humanos, Tecnos, Universitat de Lleida, Madrid, 2013, especialmente pp. 229-230. Sobre Siria, vid., entre otros, BAUTISTA HERNÁEZ, A., "Siria y las normas de Derecho Internacional sobre armas químicas: ¿una solución al conflicto?", Documento de Opinión, Instituto Español de Estudios Estratégicos (núm. 111, 12 de noviembre de 2013), en http://www.ieee.es/Galerias/fichero/docs_opinion/2013/DIEEEO111-2013_ Siria_ArmasQuimicas_A.BautistaHernaez.pdf. Sin duda alguna, las conclusiones a las que llegamos respecto a la práctica reciente -con los casos de Libia y Siria como telón de fondo, por ejemplo- no parecen mostrar un horizonte halagüeño en lo que a la responsabilidad de proteger respecta. Por ello, resultan de un enorme realismo las palabras de BERMEJO GARCÍA, R., "La responsabilidad de proteger y el derecho internacional: ¿mito o realidad internacional?", en Derecho Internacional Humanitario y Derechos Humanos. Reflexiones sobre el Conflicto Colombiano, DÍAZ BARRADO, C.M., FERNÁNDEZ LIESA, C.R., RODRÍGUEZ-VILLASANTE Y PRIETO, J.L. (dirs.), Civitas, Pamplona, 2013, p. 209, al señalar que "muchas potencias occidentales se acuerdan de los derechos humanos cuando están en juego sus intereses o creen que lo están" y por ende, afirma, "tenemos todos los ingredientes para que la "responsabilidad de proteger", tal y como se está aplicando, se convierta en una especie de arma arrojadiza, en la que el remedio es peor que la enfermedad".

${ }^{58}$ Vid. párrs. 138-139 del documento citado. Las cursivas son nuestras. 
El Secretario General de Naciones Unidas Ban Ki-moon, se mostraba cauteloso, en su Informe sobre "Hacer efectiva la responsabilidad de proteger", de 2009, al señalar, en conexión directa con lo antedicho, que "(a) menos que los Estados Miembros decidan otra cosa, la responsabilidad de proteger únicamente es aplicable a los cuatro crímenes o actos especificados: el genocidio, los crímenes de guerra, la depuración étnica y los crímenes de lesa humanidad. La tentativa de ampliarlo para abarcar otras calamidades como el VIH/SIDA, el cambio climático o los desastres naturales redundaría en desmedro del consenso de 2005 y extendería el concepto hasta un punto en que ya no sería reconocible ni tendría utilidad práctica alguna" ${ }^{59}$.

Si bien parece claro que el concepto específico de "responsabilidad de proteger", al menos tal y como se han definido sus contornos en el consenso alcanzado en 2005, tiene un campo de acción muy limitado, la frase con la que el Secretario General comienza, cuando señala "a menos que los Estados Miembros decidan otra cosa", nos presenta sin duda un concepto inacabado ${ }^{60}$. Cabe la posibilidad de que los Estados Miembros decidieran otra cosa, inclusive ampliar dicha noción; siendo optimistas, ¿cabría preguntarse si este concepto, o al menos otro de menor calado que puede cobrar valor respecto del tema que abordamos (el principio de protección de las personas en caso de desastre) pudiese entrar en juego de manera específica cuando los Estados se ven absolutamente desbordados para hacer frente a situaciones de emergencia y/o catástrofe, o cuando dichas situaciones llegasen a provocar efectos transfronterizos nocivos de especial gravedad? ${ }^{61}$.

${ }^{59}$ Véase Doc. A/63/677, párr. 10, p. 8, de 12 de enero de 2009. Esta misma posición ha sido recalcada, siguiendo la misma senda que el Secretario General, por el Relator Especial de la CDI, E. VALENCIAOSPINA, vid., "Prólogo", op. cit., p. 22. El marco limitativo que el Secretario General ha ofrecido respecto de la responsabilidad de proteger ha llamado también poderosamente la atención de la doctrina española; entre otros, recientemente De Tomás Morales, S., "Adiestramiento sensible al género y empoderamiento de la mujer: la necesidad de un enfoque integral. Formación/Adiestramiento en relación con la población civil", en DE TOMÁS MORALES, S. (dir.), AMICH ELÍAS, C., (coord.), Formación y adiestramiento sensible al género del personal cívico-militar y el empoderamiento de la mujer. Reflexiones en torno a las Operaciones de Paz en el marco de la Política Exterior y Seguridad Común de la Unión Europea, Dykinson S.L., Madrid, 2013, especialmente pp. 91-94.

${ }^{60}$ Desde hace años, la doctrina ha venido prestando atención a este tema; un completo análisis puede verse en DAVIES, S.E., "Natural Disasters and the Responsibility to Protect", German Yearbook of International Law (vol. 55, 2012), pp. 150-174; en particular, la evolución experimentada en la CDI respecto a la relación entre responsabilidad de proteger y el tema de "la protección de las personas en caso de desastre", vid. pp. 156-161.

${ }^{61}$ Sin duda alguna, el debate está servido; valgan como meros ejemplos, la pregunta que abre un debate sobre la cuestión, que lanza BOISSON DE CHAZOURNES, L., "Responsabilité de protéger et catastrophes naturelles: l'émergence d'un régime?", en La responsabilité de protéger, op. cit., pp. 149-152; o la afirmación de PRIETO SANJUÁN, R.A., "El jurista, los desastres y la construcción de la reglamentación internacional", en Derecho Internacional y Desastres, op. cit., p. 53, donde este autor se pregunta: "Precisamente, ¿cuándo estos últimos -los promotores del principio de responsabilidad de proteger- afirman enfáticamente que la responsabilidad de proteger no podría aplicarse en situaciones de desastres naturales (llamada doctrina restrictiva de la R2P) no se estaría alentando a la Comisión a redactar un proyecto de 
Sin duda alguna no se trata de un tema cerrado ni mucho menos, tal y como parece desprenderse de los trabajos que la CDI está desarrollando en la materia. El Memorando preparado por la Secretaría al respecto nos pone sobre la pista de lo antedicho, ya desde el cuadro inicial introductorio, al señalar:

"Para ser completo, cualquier régimen internacional de socorro en casos
de desastre debe tener en cuenta la protección de las personas en esas situa-
ciones de desastre. Aunque está claro que el Estado receptor es el principal
responsable de la protección, otros actores pueden desempeñar una impor-
tante función en la medida en que lo permita el derecho internacional.
En el núcleo del contenido de la protección en situaciones de desastre
se encuentran las obligaciones internacionales vigentes en materia de de-
rechos humanos. Aunque varios instrumentos no vinculantes sugieren la
existencia de un "derecho a la asistencia humanitaria" específico que sería apli-
cable en casos de desastre, la ley sigue sin pronunciarse con claridad sobre
este extremo"

La cuestión parece clara en lo que se refiere a la eventual aplicación de la responsabilidad de proteger, hecho éste señalado además en el Memorando antedicho, de manera que no arroja dudas sobre el particular:

"También debe señalarse que el concepto de la "responsabilidad de proteger", como se recoge en el Documento Final de la Cumbre Mundial 2005, no se concibió para aplicarla en el contexto de los desastres" ${ }^{63}$.

La eterna insatisfacción del jurista, que le lleva a explorar nuevos horizontes, para tratar de buscar respuestas a problemas que aún no las tienen, hace que deban reinterpretarse ciertas nociones, con el objetivo de dar cabida a otras posibilidades de actuación. La ebullición del sistema internacional actual, de la que el Secretario General de Naciones Unidas es plenamente consciente, le permitió poner el acento en diversos retos a los que la comunidad internacional ha de hacer frente:

"La cooperación de todos los Estados Miembros y entre todos los Estados Miembros es decisiva para lograr hacer efectiva la responsabilidad

artículos sobre un campo no cubierto por la responsabilidad de proteger, a saber el de la protección de las personas en casos de desastre?".

${ }^{62}$ Vid. Doc. A/CN.4/590, de 11 de diciembre de 2007, p. 3, cuadro explicativo, in fine. La cursiva es nuestra.

${ }^{63}$ Vid. ibid., párr. 250, p. 166; de manera particular, las notas a pie núms. 754-756, a las que remitimos, son especialmente ilustrativas, tanto por lo que respecta a referencias documentales como bibliográficas. 
de proteger. Trabajando de consuno en pro de nuestro compromiso compartido de proteger a las poblaciones, debemos estar dispuestos a utilizar los instrumentos que pone a nuestra disposición la Carta de las Naciones Unidas, a extraer enseñanzas de las experiencias del pasado y a reflexionar sobre cómo mejorar. Debemos seguir tratando de hacer efectiva la responsabilidad de proteger con mayor eficacia y coherencia. Sigo estando convencido de que es un concepto al que le ha llegado su momento" ${ }^{64}$.

Esa idea evolutiva es la que, de alguna manera, se pone de relieve en el Memorando de la Secretaría cuando analiza, como correlato lógico del estudio del tema de la "Protección de las Personas en caso de desastre" la existencia o no de un "derecho" (y lo escribe entre comillas, para resaltar el problema subyacente) a la asistencia humanitaria en este tipo de supuestos. La cuestión suscita dudas, tanto desde el punto de vista académico, donde las posiciones en presencia oscilan desde "la inexistencia de un derecho humano consuetudinario a la asistencia humanitaria en el contexto de los desastres naturales", pasando por quienes consideran "la existencia de dicho derecho y lo clasifican como una norma secundaria de derecho internacional", mientras que "otros entienden que dicho derecho está firmemente establecido" ${ }^{65}$. La realidad parece mostrar que habrá de ser la propia práctica en la materia, así como el establecimiento y la decantación de dichas ideas en diversos textos internacionales -si bien muchos de ellos no vinculantes-, de la mano, entre otros, del Comité Internacional de la Cruz Roja ${ }^{66}$, del Instituto de Derecho Internacional ${ }^{67}$ e inclusive de los propios trabajos de la $\mathrm{CDI}^{68}$, los que puedan permitir

${ }^{64}$ Vid. Informe del Secretario General, "La Responsabilidad de Proteger: respuesta oportuna y decisiva”, de 25 de julio de 2012, Doc. A/66/874- S/2012/578, párr. 61, in fine, p. 19.

${ }^{65}$ Vid. Doc. A/CN.4/590, párr. 257, in fine, p. 172, así como la bibliografía que se cita, a la que remitimos.

${ }^{66}$ Entre otros textos, el Memorando se refiere a los Principios y normas de la Cruz Roja y la Media Luna Roja para el socorro en casos de desastre, los Criterios de Mohonk para asistencia humanitaria en emergencias complejas, todos ellos textos elaborados en los años noventa del pasado siglo (vid. doc. citado, párr. 258, p. 172).

${ }^{67}$ Algunos años más tarde, en 2003, la resolución sobre asistencia humanitaria aprobada por esta institución señalaba que "(1)as víctimas de los desastres tienen derecho a solicitar y recibir asistencia humanitaria”. Vid. doc. citado, párr. 258, pp. 172-173. Los cauces que permitan llevar a cabo esa asistencia constituyen, sin duda, otro reto.

${ }^{68}$ La idea de prevención resulta vital; a este respecto, el Sexto Informe sobre la protección de las personas en caso de desastre, presentado por el Relator Especial el 3 de mayo de 2013 ahonda en esta idea de la prevención, así como en dos ámbitos que, a nuestro juicio resultan igualmente esenciales: derechos humanos y medio ambiente. El Informe, Doc. A/CN.4/662, es un estudio exhaustivo que analiza las raíces del principio de prevención, en conexión con los pasos que desde la Asamblea General se pusieron en marcha, junto con la práctica estatal y jurisprudencial en las materias relacionadas. Se trata 
realizar avances significativos; ello, unido a la toma de conciencia por parte de los Estados, al elaborar normas internacionales de protección civil que pongan de relieve ese "eventual derecho a la asistencia en caso de desastres" ${ }^{99}$ sin duda permitirá avanzar en esta cuestión, logrando el desarrollo progresivo en un ámbito cuyos contornos aún distan de estar claros. Por supuesto, la coordinación entre sistemas conforma la estrategia a seguir, tal y como se pone de relieve en los trabajos más recientes, ilustrativos de la labor de nuestras Fuerzas Armadas en este campo ${ }^{70}$. Su mayor implicación en este terreno implica, seguir la senda trazada hace décadas respecto a la integración de nuestras fuerzas armadas en misiones internacionales y la coordinación en los diferentes ámbitos en los que se precisa su presencia.

\section{ALGUNAS CONCLUSIONES INCIPIENTES DE UN TEMA MERAMENTE ABOCETADO}

Las líneas que anteceden tratan de ofrecer un acercamiento a un documento marco relativamente reciente, la Estrategia de Seguridad Nacional, en conexión directa con el tema abordado: las catástrofes y el tratamiento que desde la óptica del Derecho Internacional se ha intentado ofrecer a esta cuestión. Ello implica relacionar directamente diversos órdenes jurídicos, pero sin olvidar en ningún momento la perspectiva iusinternacionalista, ámbito de especialización de la persona que suscribe estas líneas. Por ello, de forma breve y meramente abocetada, se pueden plantear las siguientes conclusiones preliminares, extraídas de las líneas que anteceden.

1. La inclusión en la Estrategia de Seguridad Nacional de 2013 de las emergencias y catástrofes como riesgos a la seguridad nacional constituye un hito, que por supuesto no es ajeno a las actuaciones que desde hace décadas se

de un documento de ineludible lectura, al que remitimos. Asimismo, igualmente dentro del contexto de Naciones Unidas, resulta ilustrativa la web siguiente, conectada directamente con la Oficina de Naciones Unidas para la Reducción del Riesgo de Desastre: http://www.preventionweb.net/english/. La UNESCO también presta atención a este tema, igualmente desde la óptica preventiva, aspecto esencial desde tiempo atrás; véase http://www.unesco.org/new/fr/natural-sciences/special-themes/disaster-preparedness-andmitigation/disaster-risk-reduction/.

${ }^{69}$ Si bien los proyectos de artículos delineados por la CDI son más comedidos, de ellos sí se desprende la necesidad de preservar la dignidad humana, así como de concebir como "deber" del Estado afectado asegurar la protección de las personas y la prestación de socorro y asistencia en casos de desastre en su territorio (vid. proyecto de artículo 9.1). Como correlato lógico de ello, "corresponderá al Estado afectado el papel principal en la dirección, el control, la coordinación y la supervisión de dicho socorro y asistencia” (vid. proyecto de artículo 9.2, ambos en Doc. A/CN.4/L.776, de 14 de julio de 2010).

${ }^{70}$ Sobre este particular, véase J. SIERRA MÉNDEZ, "Protección civil y Fuerzas Armadas", en España ante las emergencias y catástrofes..., op.cit., especialmente pp. 89-97. 
vienen llevando a cabo en el contexto internacional. Diversos elementos ilustran esta idea, como la preocupación mostrada por Naciones Unidas (desde los pasos dados por la Asamblea General y el ECOSOC, hasta los más recientes que encuentran plasmación en la CDI). Por supuesto, la pertenencia de nuestro país a la UE (en cuyo contexto este tema va cobrando cada vez mayor predicamento, de lo que da muestra la reciente Decisión de 2013 que instaura un nuevo Mecanismo de Protección Civil de la Unión) no debe soslayarse.

2. Pese a que esta materia recibe cada vez mayor atención por parte de los internacionalistas, ello no quiere decir que el tratamiento de la misma sea sencillo. Para comenzar, la utilización de múltiples conceptos que no son jurídicos, ofrece diversas perspectivas de análisis, así como definiciones y utilización de términos no siempre coincidentes. De manera general, términos como catástrofe o desastre, entre otros muchos, se suelen utilizar de manera intercambiable, tanto en normas internas como internacionales. Un análisis somero, especialmente de la práctica española en la materia -en particular con nuestros vecinos, con los que la cooperación es una necesidad ampliamente sentida-ilustra esta idea.

3. El debate acerca de la posibilidad o no de "extrapolar", con la necesaria cautela, una noción cuyos perfiles aún no se encuentran del todo delimitados, como lo es la noción de "responsabilidad de proteger", a la materia que nos ocupa, resulta objeto de ineludible controversia. Los trabajos del Relator Especial de la CDI parecen ofrecer, sin ahondar en exceso en ello, algunas posibilidades de interés, especialmente poniendo de relieve la idea de asistencia a las personas en caso de desastre. Los últimos proyectos de artículos objeto de debate parecen ahondar en esa senda, con la necesaria preservación de principios básicos del contexto internacional (no injerencia, respeto de la soberanía nacional, entre otros).

4. La Estrategia de Seguridad Nacional de 2013 plantea sin duda nuevos retos. Y el tema que nos ocupa ofrece un lugar destacado entre ellos; si bien es cierto que no se trata de una materia novedosa per se. La puesta en práctica de los servicios de protección civil, y su actuación concatenada y, podría decirse, multinivel, constituye un reto para cualquier Estado o administración que haya de hacer frente a un fenómeno de esta índole. Y, dentro de este objetivo a alcanzar, las palabras prevención y coordinación constituyen elementos insoslayables. El contexto, tanto interno como internacional, permite ofrecer muestras de que la cooperación para hacer frente a los desastres - prioritariamente entre Estados vecinos o miembros de una misma organización internacional, pero no exclusivamente en dichos ámbitos-, es esencial. En ese sentido, abogar por una mayor participación de España en el contexto organizativo internacional 
(por ejemplo, en la Organización Internacional para la Protección Civil, de la que no somos miembros), con la vista puesta en la realización de actuaciones de prevención e intercambio de información entre sistemas resulta fundamental. Sí cabe argüir nuestra participación en los mecanismos auspiciados por la Unión Europea (Monitoring and Information Centre-MIC- así como en el Common Emergency Communication and Information System -CECIS).

5. Por supuesto, la inclusión de las emergencias y catástrofes dentro de los riesgos para la seguridad dota a estas situaciones de una especial relevancia. Y por ende, sitúa a nuestras Fuerzas Armadas entre los actores prioritarios -que no únicos, pues a ellas pueden/deben sumarse prácticamente el conjunto de administraciones del Estado, en todos los niveles- junto con los servicios de protección civil. Sin duda alguna, las actuaciones iniciales han de provenir de estos ámbitos, sin que ello resulte óbice, más bien hoy día al contrario, de que se solicite en ocasiones colaboración exterior (vía convencional o derivada de participación en Organizaciones Internacionales, ya sean éstas universales o regionales), especialmente cuando la situación reviste una especial gravedad que desborda los mecanismos propios para hacer frente a la misma.

6. Queda mucho por hacer, e inclusive se puede afirmar que el tema aún no ha recibido por la doctrina especializada toda la atención que el mismo reviste. Pero, sin duda alguna, la mera posibilidad de realizar aproximaciones, siquiera incipientes, a algunos de sus aspectos, contribuirá a la toma de conciencia global sobre una temática cada día más relevante.

Me gustaría por tanto finalizar las líneas antedichas, que no el tema, dado que se trata de una cuestión meramente abocetada, con un mensaje que pone de relieve la necesidad de "humanizar" el Derecho Internacional. Las palabras del profesor Carrillo Salcedo resultan imprescindibles en el actual contexto internacional de "desorden mundial" en el que vivimos:

"El interés humano se sitúa de este modo en el lugar supremo del orden de los valores, porque cada persona es un ser de fines y no un mero objeto o instrumento, con lo que la obligación de respetar los derechos humanos fundamentales se configura en Derecho Internacional contemporáneo como un principio constitucional de significación civilizadora y alcance universal en la construcción de un orden de paz"71.

${ }^{71}$ CARRILlO SALCEDO, J.A., "Permanencia y Cambios en Derecho Internacional", Discurso de Recepción del Académico de Número, Real Academia de Ciencias Morales y Políticas, 10 de mayo de 2005, p. 59. 


\section{BIBLIOGRAFÍA CITADA}

ALCAIDE FERNÁNDEZ, J., "La situación en Libia y el Consejo de Seguridad", El Cronista del Estado Social y Democrático de Derecho (núm. 20, 2011), pp. 52-59.

BAUTISTA HERNÁEZ, A., "Siria y las normas de Derecho Internacional sobre armas químicas: ¿una solución al conflicto?", Documento de Opinión, Instituto Español de Estudios Estratégicos (núm. 111, 12 de noviembre de 2013), en http://www.ieee.es/Galerias/fichero/docs_opinion/2013/ DIEEEO111-2013_Siria_ArmasQuimicas_A.BautistaHernaez.pdf.

BERMEJO GARCÍA, R., "La responsabilidad de proteger y el derecho internacional: ¿mito o realidad internacional?", en Derecho Internacional Humanitario y Derechos Humanos. Reflexiones sobre el Conflicto Colombiano, Díaz Barrado, C.M., Fernández Liesa, C.R., Rodríguez-Villasante y Prieto, J.L. (dirs.), Civitas, Pamplona, 2013, pp. 179-214.

BOISSON DE CHAZOURNES, L., "Responsabilité de protéger et catastrophes naturelles: l'émergence d'un régime?", en Société Française pour le Droit International, La responsabilité de protéger, Colloque de Nanterre, Editions A. Pedone, París, 2008, pp. 149-152.

BRATSPIES, R.M., "State Responsibility for Human-Induced Environmental Disasters", German Yearbook of International Law (vol. 55, 2012), pp. 175 216.

CARRILLO SALCEDO, J.A., "Permanencia y Cambios en Derecho Internacional", Discurso de Recepción del Académico de Número, Real Academia de Ciencias Morales y Políticas, Madrid, 10 de mayo de 2005.

CASADO RAIGÓN, R., Derecho Internacional. Parte General, Tecnos, Madrid, 2012.

CHAUMETTE, A.L., y THOUVENIN, J.-M. (dirs.), La responsabilité de protéger, dix ans après, Pedone, París, 2013.

DAVIES, S.E., "Natural Disasters and the Responsibility to Protect", German Yearbook of International Law (vol. 55, 2012), pp. 150-174.

DE TOMÁS MORALES, S., "Adiestramiento sensible al género y empoderamiento de la mujer: la necesidad de un enfoque integral. Formación/ Adiestramiento en relación con la población civil”, en De Tomás Morales, S. (dir.), Amich Elías, C., (coord.), Formación y adiestramiento sensible al género del personal cívico-militar y el empoderamiento de la mujer. Reflexiones en torno a las Operaciones de Paz en el marco de la Política Exterior y Seguridad Común de la Unión Europea, Dykinson S.L., Madrid, 2013, pp.77-126.

FERNÁNDEZ LIESA, C.R., "Desarrollos del Derecho Internacional frente a los desastres/catástrofes internacionales”, Anuario de Derecho Internacional (vol. 27, 2011), pp. 209-240. 
FERNÁNDEZ LIESA, C.R., "Desarrollos del Derecho Internacional frente a los desastres/catástrofes internacionales”, en Fernández Liesa, C.R. y Oliva Martínez, J.D., El Derecho Internacional y la Cooperación frente a los desastres en materia de Protección Civil, Dirección General de Protección Civil y Emergencias, Madrid, 2012, pp.13-41.

GARCÍA RICO, E. del M., "La gestión integrada de las zonas costeras: avances recientes”, en Juste Ruíz, J., y Bou Franch, V. (dir.), Sánchez Patrón, J.M., (coord.), Derecho Internacional y Sostenibilidad Ambiental en el Mediterráneo, ed. Tirant lo Blanch, Valencia, 2013, especialmente pp. 493-507.

GONZÁLEZ VEGA, J.A., "En torno a recientes manifestaciones de la práctica convencional española en materia de tratados de amistad y cooperación", Revista Española de Derecho Internacional (vol. XLVI, 1994), pp. 425-432.

GUHA-SAPIR, D., HOYIS, P. y BELOW, R., Annual Disaster Statistical Review 2012. The Number and Trends, Université catholique de Louvain, Bruselas, 2013, en http://reliefweb.int/sites/reliefweb.int/files/resources/ ADSR_2012.pdf.

GUTIÉRREZ ESPADA, C., y CERVELL HORTAL, M.J., El Derecho Internacional en la encrucijada. Curso General de Derecho Internacional Público, ed. Trotta, Madrid, $3^{\mathrm{a}}$ ed, 2012.

GUTIÉRREZ ESPADA, C., "La Unión Europea ante la Resolución 1973 (2011) del Consejo de Seguridad, su aplicación práctica en la "guerra civil" en Libia y el post-conflicto", en Blanc Altemir, A. (dir.), Las Relaciones entre las Naciones Unidas y la Unión Europea. Seguridad, Cooperación y Derechos Humanos, Tecnos, Universitat de Lleida, Madrid, 2013, especialmente pp. 215-239.

HANSCHEL, D., "Prevention, Preparedness and Assistance Concerning Nuclear Accidents- Effective International Legal Framework or Patchwork?", German Yearbook of International Law (vol. 55, 2012), pp. 217-251.

KOTZUR, M., "European Union Law on Disaster Preparedness and Response", 55 German Yearbook of International Law (2012), pp. 253-278.

LANGEAIS, J., Les Nations Unies face aux catastrophes naturelles: Étude du Bureau du Coordonnateur des Nations Unies pour les secours en cas de catastrophe (U.N.D.R.O.), París, L.G.D.J., 1977.

LEBEN, Ch. y CARON, D.D., Les aspects internationaux des catastrophes naturelles et industrielles/The International Aspects of Natural and Industrial Catastrophes, Martinus Nijhoff Publishers, Dordrecht, Boston, Londres, 1996.

MACALISTER-SMITH, P., International Humanitarian Assistance. Disaster Relief Actions in International Law and Organization, Martinus Nijhoff Publishers, Dordrecht, Boston, Lancaster, 1985.

Société Française pour le Droit International, La responsabilité de protéger, Colloque de Nanterre, Editions A. Pedone, París, 2008. 
OLIVA MARTÍNEZ, J.D., "Marco Jurídico Internacional y Europeo de la Protección Civil", Anuario de la Facultad de Derecho de la Universidad de A Coruña (vol. 14, 2010), pp. 605-634.

OLIVA MARTÍNEZ, J.D., "Marco Jurídico Internacional y Europeo de la Protección Civil", en El Derecho Internacional y la Cooperación frente a los desastres en materia de Protección Civil, Dirección General de Protección Civil y Emergencias, Madrid, 2012, pp. 45-82.

PRIETO SAN JUÁN, R.A., "El jurista, los desastres y la construcción de la reglamentación internacional", en Derecho Internacional y Desastres, Estudios sobre Prevención y asistencia a víctimas, CEDI, CEDIN, Grupo Editorial Ibáñez, Bogotá, 2011, pp. 29-40.

RODRÍGUEZ CARRIÓN, A.J., El Derecho Internacional en el umbral del siglo XXI, Lección de Apertura del Curso Académico 1999-2000, Universidad de Málaga, 1999.

SIERRA MÉNDEZ, J., "Protección civil y Fuerzas Armadas”, en España ante las emergencias y catástrofes. Las Fuerzas Armadas en colaboración con las autoridades civiles, Ministerio de Defensa, Instituto Español de Estudios Estratégicos, enero de 2014, pp. 69-97.

TALAVERA ESTESO, F, "El Sistema Nacional de Protección Civil”, en España ante las emergencias y catástrofes. Las Fuerzas Armadas en colaboración con las autoridades civiles, Ministerio de Defensa, Instituto Español de Estudios Estratégicos, enero de 2014, pp. 19-68.

TESTART, J., "Regards pluridisciplinaires sur les catastrophes écologiques", en Les catastrophes écologiques et le droit: échecs du droit, appels au droit, Lavieille, J.-M., Bétaille, J. y Prieur, M., Bruylant, Bruselas, 2012, pp. 31-58.

THOUVENIN, J.-M., "L'internationalisation des secours en cas de catastrophe naturelle", Revue Générale de Droit International Public (tomo 102, 1998-2), pp. 327-363.

THOUVENIN, J.-M., "La définition de la catastrophe par la CDI: vers une catastrophe juridique?", en Prieto Sanjuán, R. y Thouvenin, J.-M., Derecho Internacional y Desastres. Estudios sobre Prevención y asistencia a víctimas, CEDI, CEDIN, Grupo Editorial Ibáñez, Bogotá, 2011, pp. 41-50.

TORRES CAZORLA, M. I., "La Comunicación de la Comisión Europea de 2010: nuevas medidas para mejorar la reacción de la UE en caso de catástrofe", en Prieto Sanjuán, R. y Thouvenin, J.-M. (eds.), Derecho Internacional y Desastres, Derecho Internacional y Desastres. Estudios sobre Prevención y asistencia a víctimas, CEDI, CEDIN, Grupo Editorial Ibáñez, Bogotá, 2011, pp. 85-110.

TORRES CAZORLA, M.I., "Environmental Security: an Initial View from the Perspective of International Law", en García Rico, E.M. y Torres Cazorla, M.I. (coords.), La seguridad internacional en el siglo XXI. Nuevas 
Perspectivas, Plaza y Valdés Editores, Universidad de Málaga, Madrid, 2011, pp. 145-166.

TORRES CAZORLA, M.I., "Las catástrofes: una visión desde la regulación internacional y de la Unión Europea”, en VI Jornadas de Seguridad, Defensa y Cooperación. Libro de Actas, 13, 14 y 15 de noviembre de 2012, Foro para la Paz en el Mediterráneo y SPICUM, Málaga, 2013, pp.31-53.

VALENCIA-OSPINA, E., "Prólogo", en Prieto Sanjuán, R. y Thouvenin, J.-M., Derecho Internacional y Desastres. Estudios sobre Prevención y asistencia a víctimas, CEDI, CEDIN, Grupo Editorial Ibáñez, Bogotá, 2011, pp. 19-24.

VEGA FERNÁNDEZ, E., "La Unión Europea frente a las catástrofes: ¿es factible una unidad multinacional europea para emergencias?", en http:// www.ieee.es/Galerias/fichero/colaboraciones/2011/UE_FrenteaCastratofes_OPEX.pdf.

VV.AA., España ante las emergencias y catástrofes. Las Fuerzas Armadas en colaboración con las autoridades civiles, Ministerio de Defensa, Instituto Español de Estudios Estratégicos, enero de 2014. 